\title{
Central East Pacific Flight Routing
}

\author{
Shon Grabbe ${ }^{*}$, Banavar Sridhar ${ }^{\dagger}$, and Parimal Kopardekar \\ NASA Ames Research Center, Mofeit Field, CA, 94035 7000 \\ Nadia Cheng ${ }^{8}$ \\ University of California-San Diego, La Jolla. CA, 92093-04TI
}

\begin{abstract}
With the introduction of the Feleral Ayiation Administration's Advanced Tochnology and Oceanic Procedures system at the Oakland Ocenaic Center, a level of automation now exists in the oceanic environment to potentially begin accommodating increased user preferted rowling requests, This paper presents the results of an initial feasibility assessment which examines the potential benefits of transitioning from the fixed Central East Pacific routes to user preferred routes. As a surrogate for the actual user-provided routing requests, a minimum-travel-time, wind-optimal dynamic programming algorithm was developed and utilized in this paper. After first describing the charactoristics (e.g*, origin airport, destination airport, vertical distribution and temporal distribution) of the westbound flights utilizing the Central East Pacific routes on Dec. 14-16 and 19-20, the results of both a flight-plan-based simulation and a wind-optimal-based simulation are presented. Whereas the lateral and longitudinal distribution of the aircraft trajectories in these two simulations varied dramatically, the number of sinulated first-Ioss-of-separation events remained relatively constant. One area of concern that was uncovered in this initial analysis was a potential workload issue associated with the redistribution of traffic in the oceanic sectors due to the prevailing wind patterns.
\end{abstract}

\section{Introduction}

$T$ he Oakland Oceanic Flight Information Region (FIR) (or Center), which is shown in Fig. 1, controls approximately 21.3 million square miles of airspace and horders the Anchorage FIR to the North, the Tokyo FIR to the East, the Aukland FIR to the South, and the coastline of the contiguous United States on the West[1]. In contrast, the twenty Air Route Traffic Control Centers (ARTCCS) in the contiguous U.S. encomapass roughly 3 million square miles. Despite the vast amount of airspace eontrolled by this Center, flights, for the most part, are required to fly along fixed route structures and adhere to latexal separation standards that extend up to $100 \mathrm{nmi}$, longitudinal separation standards extending up to 15 minutes, and vertical separation standards of 1000 ft [2]. These stingent separation standards are required because of the litaited surveilfance capabilities in the ocean and the FAA's legacy Qceanic Display and Planning System (ODAPS). It is worth noting that both the lateral and longitudinal separation standards can be significantly teduoed for Automatic Dependent Survellance - Contract (ADS-C) equipped flights that are operating in regions of the Pacific that are designated for Required Navigation Performance (RNP) [2].

\footnotetext{
'Research Scientist, Automation Concepts Research Btanch, Mail Stop 210-10, E-mail: Shon.R.Grabbe@nasa.gov.

${ }^{\dagger}$ Chief, Automation Concepts Research Branch, Mail Stop 210-10, Tellow AlAA

¿ Project Manager, Advanced Air Transportation Technologies Office, Mail Stop 210-15

${ }^{8}$ Student Dept of Mochanical and Aerospace Engineering 


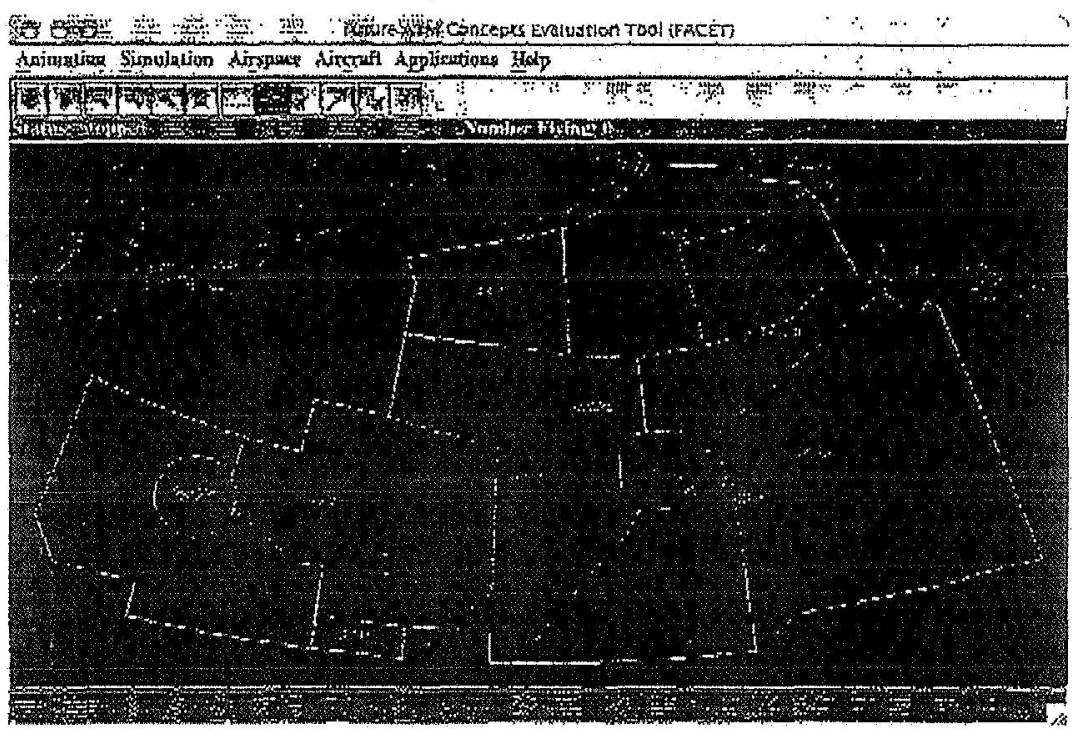

Figure 1. Oakland Oceanic Center Display Including Sector Boundaries and Coastal Map

With the introduction of the FAA's new Advanced Technologies \& Oceanic Procedures (ATOP) at Oakland Center in 2005, increased route flexibility and reduced separation standards can potentially now be accomanodated. Some of the major ATOP innovations leading to this increased flexibility are (1) fully integrated flight- and radardata-processing capabilities, (2) conflict-detection capabilities, and (3) satellite dat3-link communication and surveillance capabilities [3]. This paper presents the results of an initial study, which exanines the potential benefits and consequences of allowing user-prefented routing in place of the fixed Central East Pacific (CEP) routes.

The CEP routes shown in Fig. 2 connect the west coast of the United States to Hawaii. The alphanumeric designators for these seven routes are R463, R464, R465, R585, R576, and R577. Sectors OC-3 and OC-4 in the Oakland Oceanic FIR handles traffic along these routes. Routes RA64 and R576 ate used exclusively for westbound traffie, while routes R465, R.585, and R577 ate used exelusively for eastbound traffic. Routes R463 ard R578 canth accommodate bi-directional traffic. The RNP for aircraft flying on the CEP routes is 10 , or RNP-10, which implies that the total borizontal position error of the aircraft camnot exceed $10 \mathrm{nmi}$ for more than $95 \%$ of the flight time [2], [4]. These flights can bo identified by the " $\mathbb{R}$ " equipment suffix appearing in their International Civil Aviation Organization (ICAO) flight plans. [5]. Based on the required equipage level for flights operating on the CEP routes, the lateral separation standards are 50 mon, the longitudinal separation standards vary between 5 and 10 minutes, and the vertical separation standards are $1000 \mathrm{ft}$.

To our krowledge, this is the first study designed to explore the benefits of transitioning from the fixed CEPbasted toute structure to a mote flexible user-preferred routing structure. Though the flight routing application in this study is believed to be unique, the general area of flight plan routing and flight path design has a loxag history [6]. Recent advances in this area include the conflict-free, wind optimal routing work that was introduced in Ref. 7, the dynamic network flow rerouting approach introduced in Ref. 8, and the fleet assignment and routing approach introduced in Ref. 9. A comprehensive summary of many of the earliest flight routing techriques can be found in Ref. 10 . 


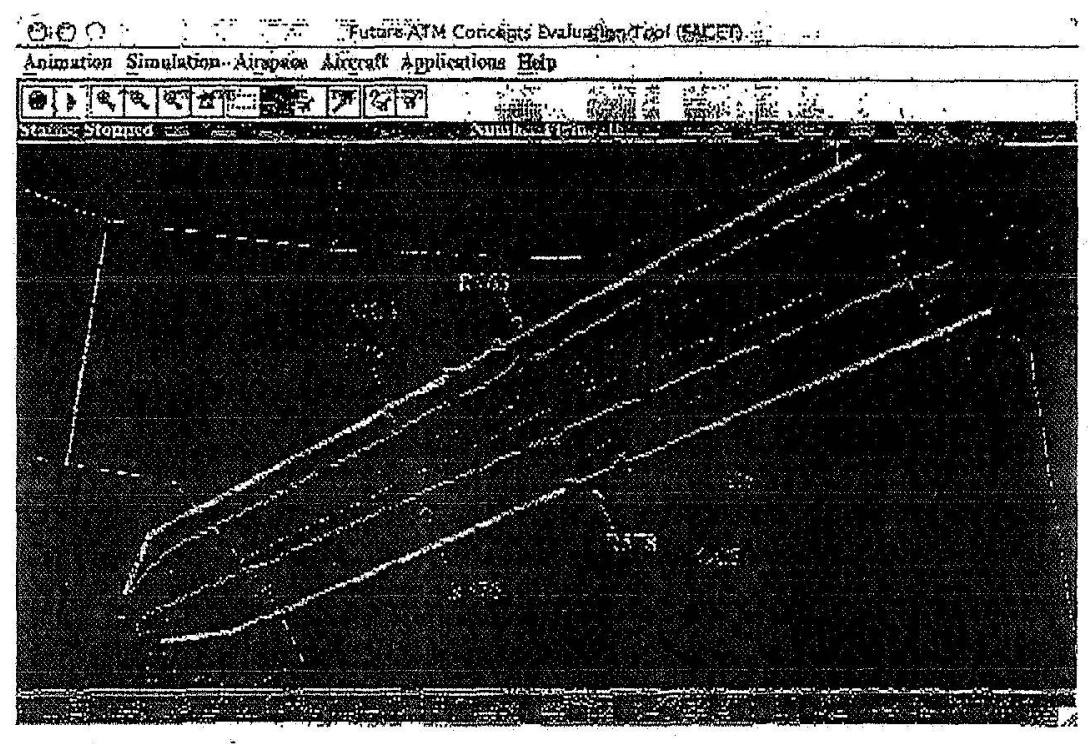

\section{Figure 2. Central East Pacific (CEP) Routes}

The rest of this paper is organized as follows. Section II describes the windmoptixnal routing methodology that was adopted for this paper. The unmodified characteristics of the CEP routes are described in Section III and the modeling results are presented in Section IV. Finally Section V section exds with sume conclusions.

\section{Modeling Methodology}

As previously mentioned, the FAA's new ATOP system offers ax unprecedented level of automation in comparison to the legacy ODAPS system that it replaced. With this new system, it is now conceivable to transition from the fixed CEP route structure in the Pacific to a set of routes that accommodate the airline user's preferences. To begin understanding the potential implications of this transition, a minimum-travel-time, wind-optimal dynamic programming algorfithm was developed to simulate possible user toute preferences. Though the business models, schedules, and aerodynamic performatrce chatacteristics (c.s., ongine type, weight, etc.) of the aircraft in the airline's fleet will ultimately govern the design of the optimal trajectories each aitline wishes to fly, a sixpple minimum-time wind-optimal model, as adopted in this study, should initially suffice to understand this change in routing pinilosophy.

For the purpose of this study, the position of an aircraft along a minitruma-time wind-optimal route at stage $k+1$ can be related to the position at stage $k$ via the following equation:

$$
x_{k+l]}=x_{k}+u_{k}
$$

Here $u_{k}$ is the decision variable at stage $k$. For the purpose of this study, wind optimal routes are calculated on a grid composed of latitude and longitude values that encompass the region of airspace in which each analyzed aircraft travels. Though the grid is individually tailored for each flight, the grid is roughly bounded between the $20^{\circ} \mathrm{N}$ latitude to the south, $40^{\circ} \mathrm{N}$ latitude to the north, $156^{\circ} \mathrm{W}$ longitude to the west, and $120^{\circ} \mathrm{W}$ longitude to the east. This grid is sufficient for most flights that either depart or arrive at the west cosst of the United States. For flights departing or arriving at in-land airports, such as Chicago O'Hare International Airport, the grid is increased accordingly.

The stages, $k$, within our problem formulation refer to the available longitudinal values: the states $x_{k}$ refer to the latitude values; and the decision variables, $u_{k}$, are the changes in the latitude values that are perrnitted at each stage $k$. The bounds on the decision variables and the states are

$$
\lambda_{\text {mall }, k} \approx x_{k} \leqslant \lambda_{\text {max }, k}
$$




$$
u_{k} \in U_{k} \quad \text { where } \quad U_{k}=\left\{u_{k} \mid-5 \leq u_{k} \leq 5\right\}
$$

Additional bounds are applied to $x_{k}$ at the first and lest stages to ensure the route starts and ends at the entry and exit points of the CEP routes into the Oakland Oceanic FIR. This additional constraint is applied to enforce any procedural constraints that might apply as an aircraft transitions to/from a U.S. Air Route Traffic Control Center (ARTCC) and the oceanic enviromment.

Using the principle of optimality, the minimura cost function at stage $k, I(x, k)$, can be calculated from the minimum cost function at stage $k+l, I\left(x_{k}+u_{k}, k+1\right)$ using the following expression [11]:

$$
I(x, k)=\min _{u_{k} \in U_{k}}\left\{C\left(x_{k}, u_{k}, k\right)+I\left(x_{k}+u_{k}, k+1\right)\right\} \text { for } k \in\{0,1, \ldots, N-1\}
$$

Here $C\left(x_{k}, h_{k}, k\right)$ is the cost associated with transitioning from state $x_{k}$ to $x_{k+1}$ using the decision variable $u_{k}$ at stage $k$. For our study, the cost is equal to the amount of time required for an aircraft to fly from the current state, $x_{k}$, to the taext state, $x_{k+1}$. The details of the cost function calculations are provided in Appendix A. The sequence of controls (i.e. $u_{0}, u_{1}, \ldots, u_{N-1}$ ) resulting from the solution of Eq. 5 for $0 \leq k \leq N-1$ is used to construct the minimum-time, wind-optimal routes between the origin and destination airport for each flight. For all routes generated using Eq. 4 , the minimum cost function at $k=N(i-\mathrm{z}-l(x, N))$ has been set to zero.

To illustrate the use of this algorithm, wind optimal trajectorics for the wastbound aircraft that were nominally flying on the CEP routes are presented in the fourth section of this paper.

\section{Unmodified Flow Characteristies}

The primary purpose of this section is to describe the data sourees used in this study and to farniliarize the reader with the nominal characteristics ( $e, g$, number of aircraft, vertical distribution, etc.) of the westbound traffic flying along the CEP routes. Airotat flight plans, flight plan amendments, departure times, artival times, and position reports were obtained from an Airctaft Situation Display to Industry (ASDI) data feed [12], [13] for Dec. 14-16 and 19-20 of 2005. For reference, Dec. $14^{\text {th }}$ is a Wednesday and Dec. $20^{\text {th }}$ is a Tuesday. To filter the westbound CEP route traffic from the national data mosaic provided by the ASDI data feed, only flights that explicitly contained $R 463, R 464, R 576$, atd $R 578$ in either a fight plan or flight plan amendment message were retained for further processing. The resulting aircraft counts for this five-day period are shown in Fig. 3. A total of 325 westbound flights were analyzed during this time period. The average daily traffic count was 65 and the standard deviation was 4.6. 


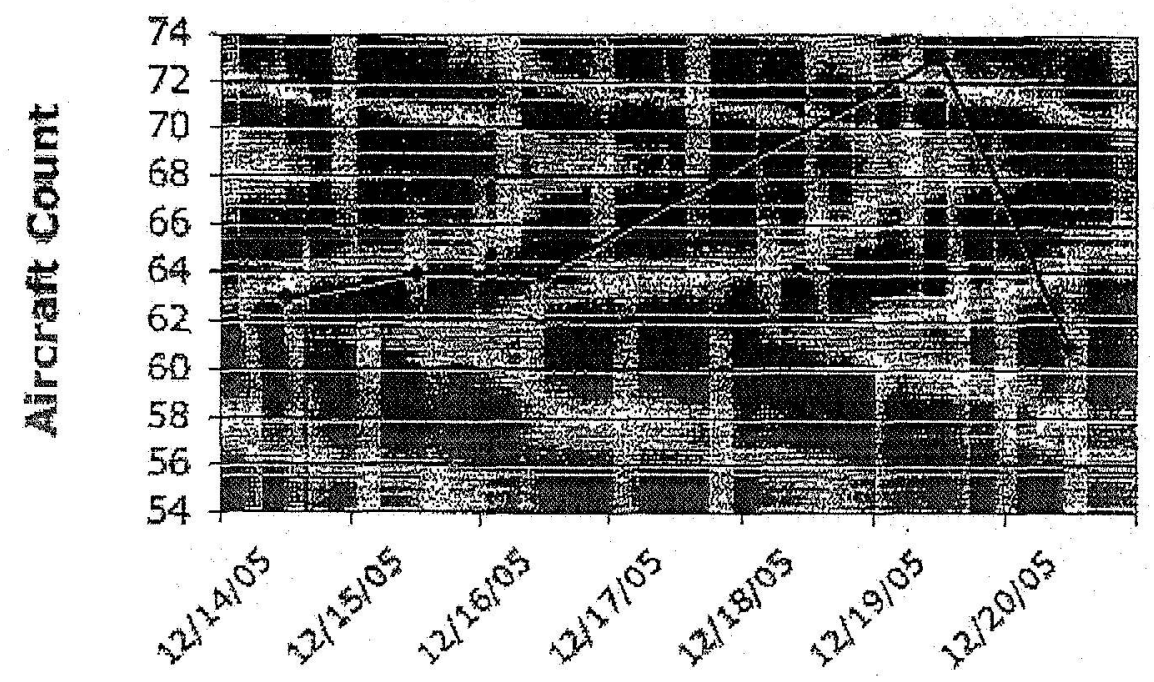

Figure 3. Westbound Traffic Couxts on the CER Routes

To assess the vertical distribution of the westbound flights, the actual flight level (FL) of ach aircraft as it crossed $140^{\circ}$ west longitude, which is roughly halfway between Hawaii and the U.S. mainland, wras recorded and the results are displayed in the leftmost image in Fig. 4. As can be seen from this figure, the most predominartily uged flight level was FL340 (or $34,000 \mathrm{ft}$ ), and approximately $73 \%$ of the airctaft were between FL 320 and FL 360 .

The rightmost inage in Fig. 4 depicts the temporal distribution of the westbound flights at $140^{\circ}$ west longitude. As can be seet foom this figure, the largest concentration of filights cross this longitude at roughily 19-00 UTC, which corresponds to a west-coast departure tithe of approximately 16:30 UTC (or 8:30 PST). The traffic count distribution on each of the analyzed days shows little vatiation, but slightily more aircraft were observed to cross this longitude at 6:00 UTC and 21:00 UTC on 12/19/05, which is a Moxday.
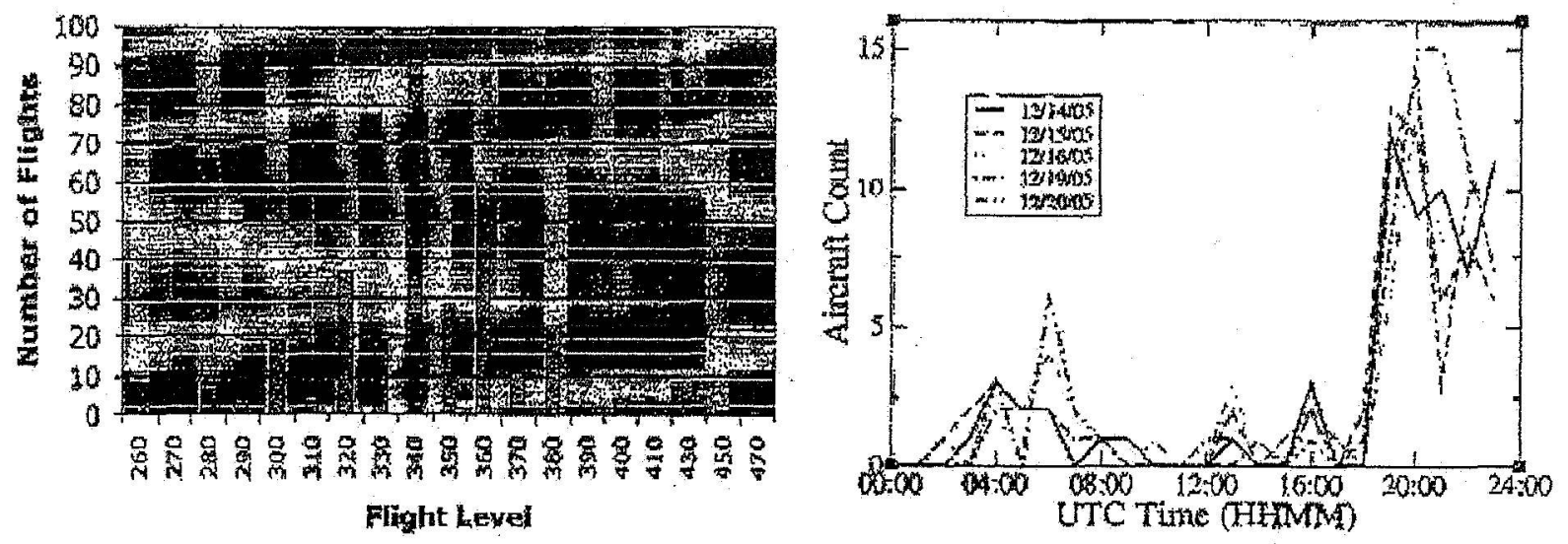

Figure 4.Vertical (left) and Temporal (right) Distribution of the West-Bound Flights at 140 degrees West Longitude

The leftnost image in Fig. 5 depicts the departure airport usage statistics for the westbound CER flights, while the rightmost image shows the corresponding destination sirport statistics. For the departuro statistics, onty the top 15 airports are illustrated, although flights were observed to depart from 40 airports during the five-day period 
analyzed in this study. Roughly $42 \%$ of all westbound flights departed from Los Angeles International Airport, $\mathrm{KIAX}$, and San Francisco lnternational Airport $\mathrm{KSFO}$. The tatmes associated with the remaining departure airport acronyms in Fig. 5 follow: Chicago O'Hare (KORD), McCarran Intl. (KLAS), Phoenix Sky Harbor Intl. (KPHX), John Wayne Airport (KSNA), Dallas/Fort Worth Intl. (KDFW), Metropolitan Oakland Intl. (KOAK), San Diego Intl. (KSAN), Memphis Intl. (KMEM), Ontario Intl. (KONT), Seattle-Tacoma Intl. (KSEA), Norman X. Mineta San Jose Intl. (KSIC), Portland Intl. (KPDX), and Sacramento Intl. (KSMF).

The arrival airport statistics that are shown in the rightmost image in Fig. 5 , illustrate that approximately $60 \%$ of all flights destined for Hawaid landed at Honolulu toth. Airport (PHND). In contrast, only one flight was observed to arrive at Lanai (PHNY) and Hilo (PHTO) during the same period. Of the remaining flights, $24 \%$ landed at Kahului (PHOG), $11 \%$ landed at Kona/Keahole Kailua (PHKO), and $4 \%$ landed at Lihue/Kauai Island (PHLD).
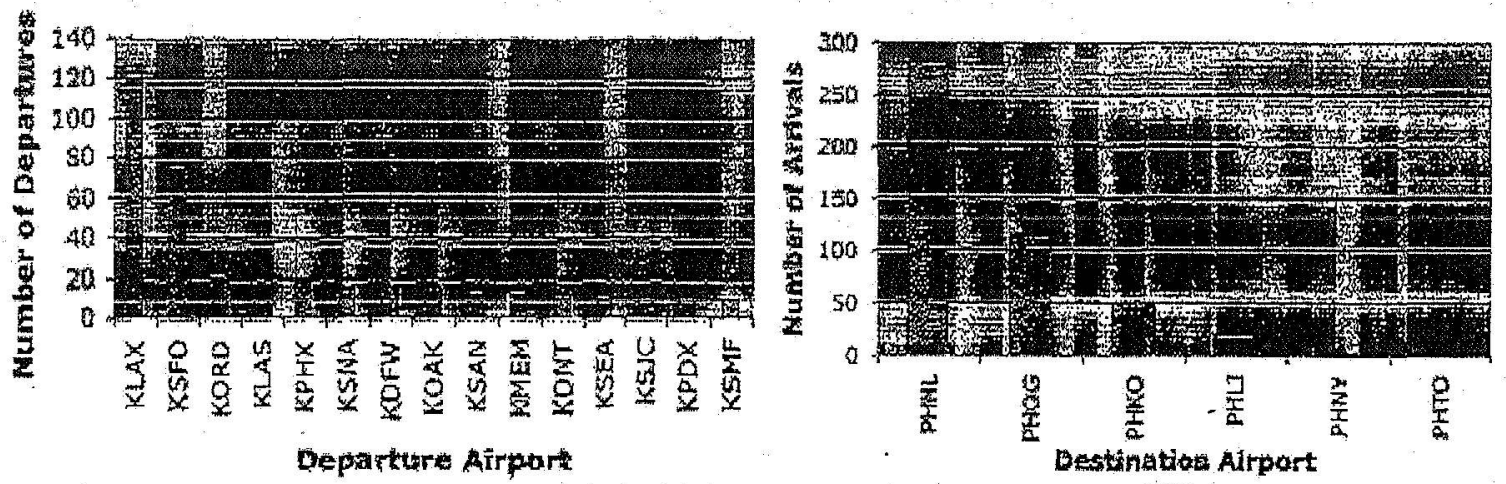

Figure 5. Top Origin and Destination Airports for the Westhound Fights

The distribution of the flishts anongst the avallable westbound CEP routes is shown in Fig- 6. As shown by this figute, ffights traveled predominately along $\mathrm{R} 464$ and $\mathrm{R} 576$, which are both undirectional routes. Sigtificantly, less traffic was observed along $\mathrm{R} 483$ and $\mathrm{R} 578$, which are bi-directional routes. The control of flights along these routes was distributed roughly evenly between Oakland Oceanic Sectors 3 and 4 . As illustrated by Fig. $X$, traffic on R463 and $R 464$ is controlled by Sector 3, while traffic on R 576 and R578 is controlled by Sector 4 .

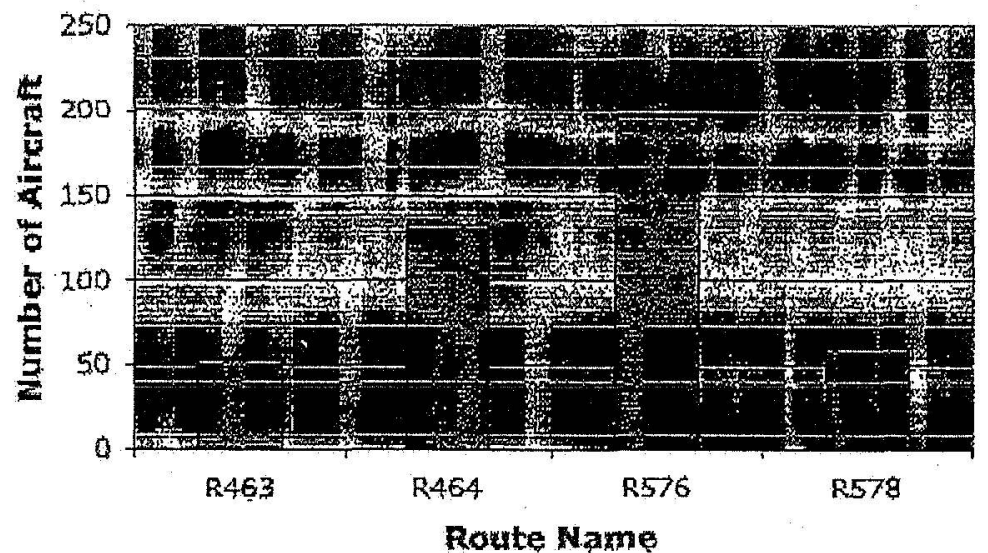

Figure 6. Westbound CEF Route Usage Statisties 


\section{Modified Flow Characteristics}

The results from an initial set of simulations that were designed to access the potential benefits and consequences of allowitg flights to deviate from the fixed CEP route structure in favor of user-preferred routes are presented in this section. Using the ASDI data files for Dec 14-16 and 19-20 of 2005 , two sets of simulations were rum in the Future ATM Concepts Evaluation Tool (FACET) [14]. In the first set of simulations, flights were allowed to fly along their filed flight plans, as specified in the ASDT files, while in the second set of simulations a wind optimal trajectory was calculated for each flight using the methodology outlined in Section II. For both sets of simulations, only aircraft that filed flight plans on one of the four westbound (i.e. R463, R464, R576, and R578) CEP routes were retained from the original ASDI files.

The magnitude and diection of the withds in the pacifie ocean that were used to simulate the trajectory of the aircraft on both the original flight plan route and the wind optimal route were obtained from the Global Forecast System (GFS) Atmospheric Model [15] that is produced by the National Oceanic and Atmospheric Administration (NOAA). For reference, GFS is a global atmospheric model with a horizontal resolution of approximately $-0.5^{0} \mathrm{x}$ $0.5^{\circ}$ latitude/Tongitude and an unequally spaced vertical resolution starting at $1000 \mathrm{mb}$ (surface) and extending up to $100 \mathrm{mb}$. Wpdates to the GFS model are available every six hours and forecasts are available up to 16 days into the future. As an example of the wind data used in the simulation, the wind magnitude contours at $250 \mathrm{mb}$, which roughly includes the altitudes between $31,000 \mathrm{ft}$ and $36,000 \mathrm{ft}$, are shown in Fig. 7. For reference, the Hawailan Islands are shown at the bottom left of this rigure and the west coast of the United States is shown on the tight side of this image, A region of very strong, easterly winds ( $>120 \mathrm{knots}$ ) is designated by the magenta polygon in the center of this figure and lies directly above two of the westbound CEP routes (R576 and $R 578$ ).

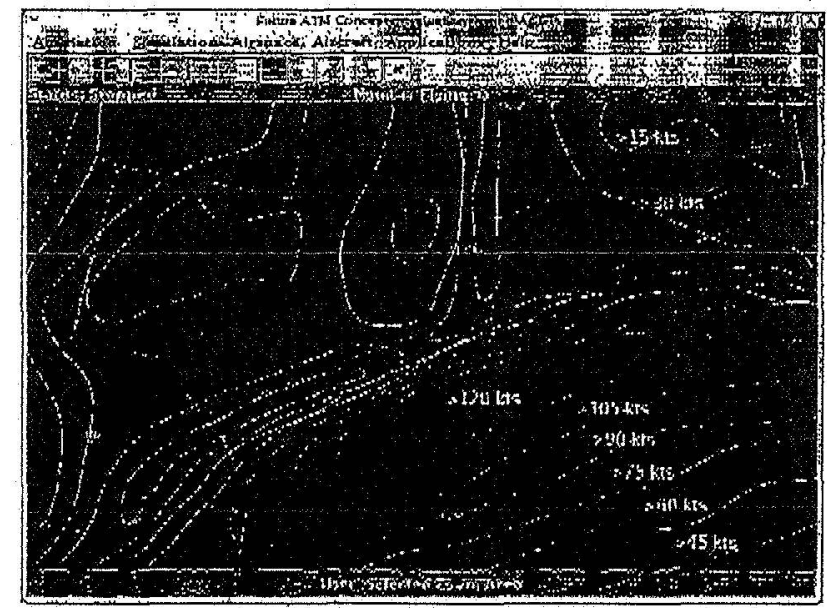

Figure 7. Wind contours at 250 mb in the Central Gast Pacific

The aircraft position (latitude and longitude) histories for the flight plan and wind optimal based simulations that were run using the ASDI data for Dec. 14, 2005 are displayed in Fig. 8. The leftmost image in this figure depicts the westbound position histories for aircraft on the CEP-baged flight plan routes, and the rightmost image depicts the position histories for the flights on wind-optimal routes. Only minor deviations in the magnitude and direction of the wind-field were observed in the Central East Pacific on Dec. 14, 2005, so only a single GFS file (0:00 UTC, zero-hour forecast file) was used to generate these results. The most striking feature differentiating these two images is the tremendous latitudinal and longitudinal dispersion of the airoraft position histories resulting from the wind-optimal routing simulation. Not only are the histories dispersed but, with only one exception, the routes have all been shifted north because of the strong easterly winds present in Sector 3 , see Fig. 8. When getheratitis the wittd optitual toutes, eqch atretaft has been allowed to thy a wind optimal trajectory from the origin airport to the destination airport. Alternative wind optimal strategies to be explored in the final draft of this paper include the following:

1. Fixed routing in the ARTCC atrspace and wind optimal routing only in the oceanic envirothtent

2. Frind optimal routing along a foxed number (6., 2-3) of dymamically generated rotites 

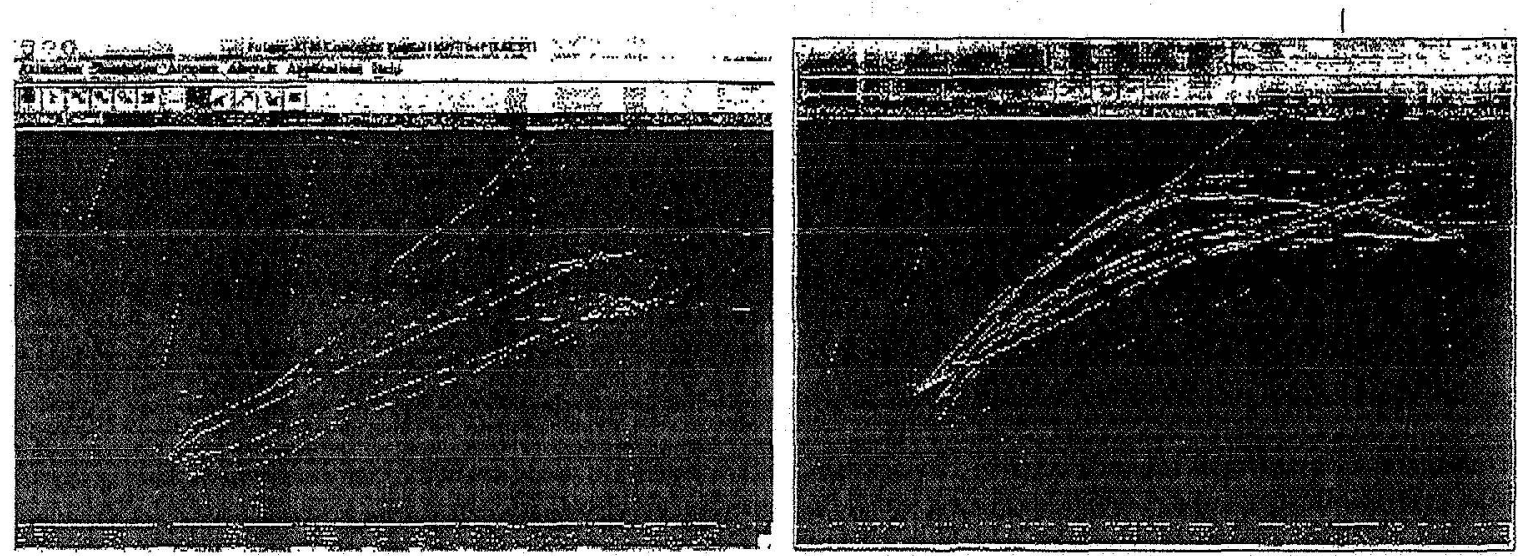

Figure 8. Flight Plan and Wind Optimal Routes for Wasthound Wlights

The sector counts as a function of time for Oakland Oceanic Sectors 3 and 4 are shown in Fig. 9 for both the CEP-based and wind-optimal routing simulations. The thick red and blue curyes in this figure correspond to the CEP-based routing simulations, while the thin red and blue ourves correspond to the wind optimal routing simulation. As can be seen from this figure, the impact of transitioning to wind optimal routes results in a decrease in the peak aircraft count in Sector 3 from eleven to one, and an increase in the peak aircraft count in sector 4 from 18 to 27. Ftom a controller workload perspective, the $50 \%$ increase in the peak traftic count in Sector 4 is a bit disconcerting. To accommodete the changes in the traffic patterns that could potentially be associated with adopting user preferred trajectories, resource scheduling algorithms [16] or dynamic re-gectorization [17] may prove beneficial. Both these areas of work will be explored in more detail in future studies.

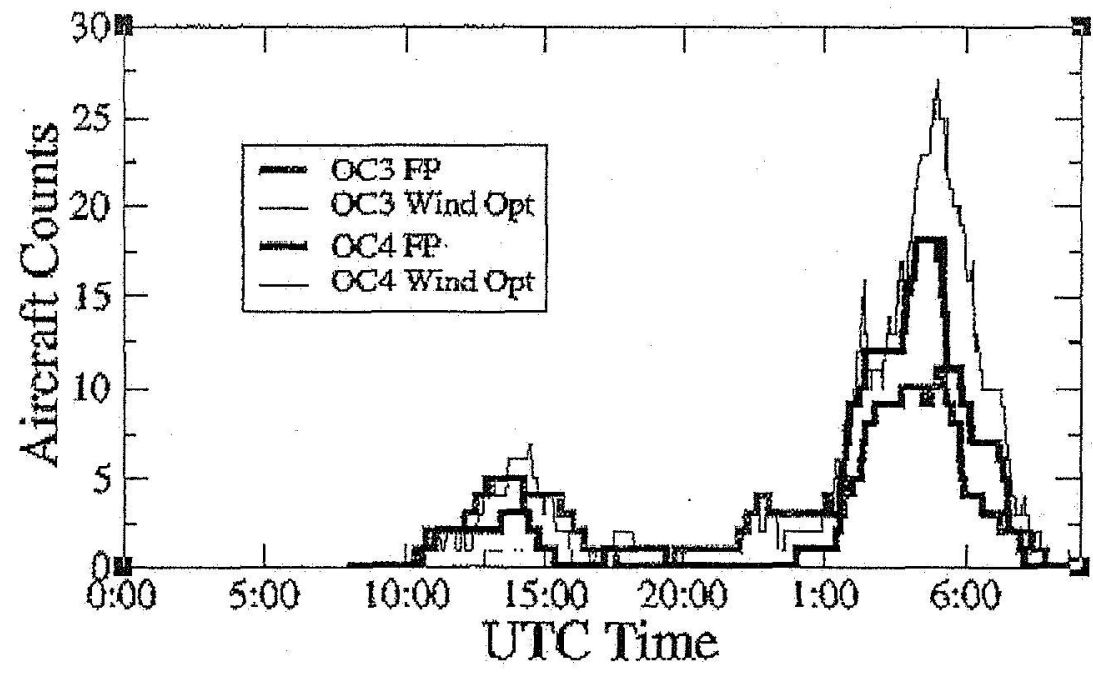

Figure 9. Aircraft Counts in Oakland Sectors 3 and 4 with wind optimal and CEP routing

Chenges in the trafhic patterns in the Central East Pacific can not only increase the workload of a controller, but also can give tise to an increase in the number of possible losses of separation. Using FACET, the simulated trajectories for all westbound flights were examined for possible losses of separation on both the nominal CERbased flight plan routes and the wind-optimal routes. Losses of separation were identified under two different separation critena (1) $30 \mathrm{nmi}$ lateral spacing, 30 ani longitudinal spacing, and $1000 \mathrm{ft}$ yertical spacmg and (2) 50 
nni lateral spacing, $50 \mathrm{ami}$ longitudinal spacing and 1000 ft vertical spacing. For the remainder of this section, the first of these two separation standards will be referted to the "30/30" separation standard and the later of these two will be referred to as the "50/50" separation standard. Both of these separation standards are technically less restrictive than the standards that curretity exist for flights on the CEP routes, though the $50 / 50$ separation standards are achievable with the current ATOP system and the $30 / 30$ separation stardards are proposed reductions in the separation standards [2]-[3]. The geographical location of each unique, first-lossmof-separation event is depicted in Fig. 10. The leftmost image in this figure depicts these events with the $30 / 30$ separation standards, while the righturnusl image depicts these events with the 50/50 separation standards. Red circles are used to denote the CEP. based routing firgt-loss-of-separation events and blue squares are used for the wind-optimal events. Under both separation scenarios, the wind-optimal touting changes the location and froquency of the potential first-loss-ofseparation events. The most striking feature to note regarding the location of the events is the large number of events that occur immediately upon entcring the Oakland Oceanic Center. This would seem to indicate that additional departure constraints are required for each flight to onsure that the separation standards are met prior to passing control of flights from the domestic Centers to Oakland Oceanic. In addition, more first-loss-ofuseparation events are observed in Oakland Oceanic Sectors 4 and 7 under the wind-optimal routing scenario than the CEP. based routing scenario. This behavior is to be expected given the lack of structure and the numetous converging flight paths that are observed in Fig. 8 for the flights on wind-optimal toutes.

In regards to the frequency of first-loss-of-separation events, the $30 / 30$ scenarios yielded five events under the CEP-based routing simulation and four events for the wind-optimal routing simulation. As would be expeoted, the number of farst-loss-of-separation events increased under the $50 / 50$ scenanio, yielding six events for the CEP-based routing simulation and 12 events for the wind-optimal routing simulation.
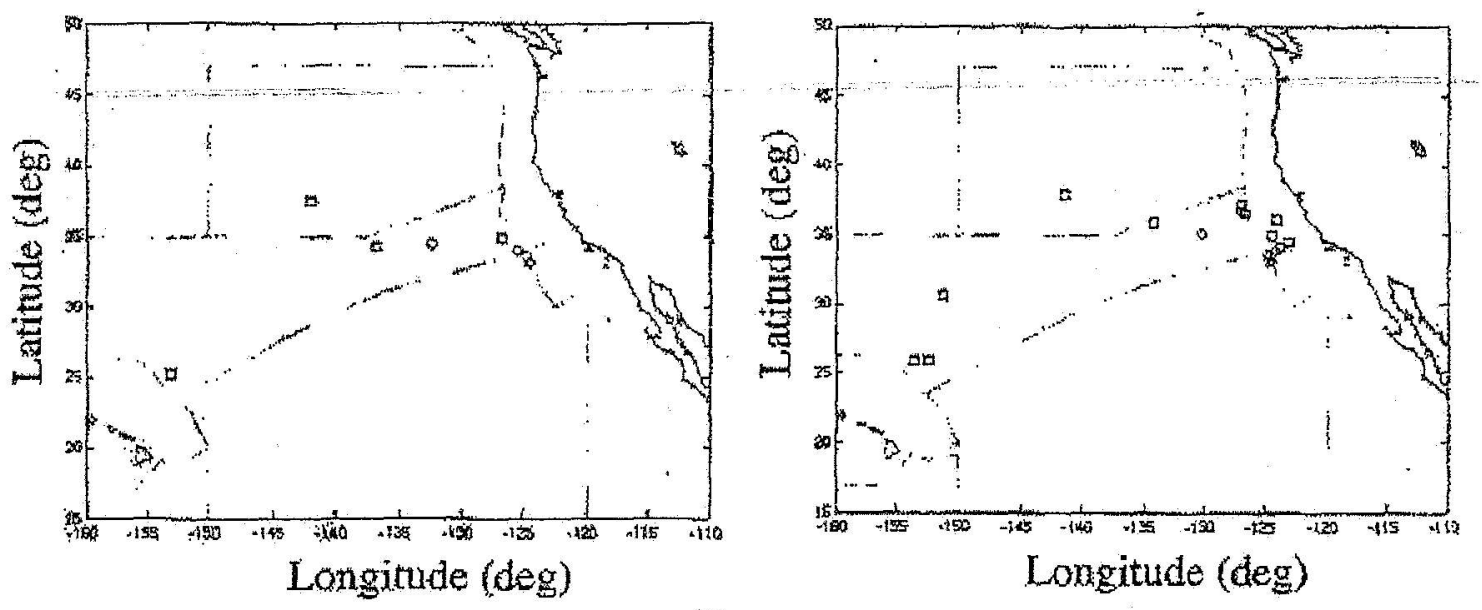

Figure 10. First-Loss-of-Separation Locations for Wind Optimal and CEP routing using $30 / 30$ (left) and 50/50 (right) latitudjual//ongitudinal separation standards

In the final draft of this manuscript, the sector count and first loss of separation analyses conducted for the westbound flights on Dec. 14, 2005 will be expanded to include the traffic from Dec. 15, 16, 19, and 20. In addition, the eastbound flights will also be examined. Additional metrics to be examined in the final draft include changes in travel time and distonce.

\section{Conclusion}

With the introduction of the FAA's new ATOR system at Oaklatd Center, incrcased route flexibility atd reduced separation standards can potentially now be accomnodated. The results of an initial study that were destgned to (1) understand the characteristics of traffic on the westbound CEP routes and (2) to assess the feasibility of transitioning from the CEP routes to user-preferted ones were presented. To accomplish the first of these two tasks, the ASDI data for Dec. 14-16 and 19-20 was used to examine the following ortgin and destination of flights on the CEP 
routes, usage of each route, vertical distribution of traftic on all routes, and the temporal distribution of flights on the rontes.

As a surrogate for the user-preferred routes, a dynamic programming based methodology was presented and used to calculate wind optimal trajectories for the westbound flights that originally flew on CEP routes; The sector counts for Oakland Oceanic Sectors 3 and 4 and the location of the simulated first loss of separation events were compared for flights on both the wind optimal routes and the nominal CEP-based flight plan routes. Though the lateral and longitudinal distribution of flights was observed to change dramatically with the wind optimal routing the number of lixst-loss-of-separation events was not observed to change significantly.

\section{Appendix A}

For the current study, the cost associated with transitioning from an initial state, $x_{k}$, to a final state, $x_{k+1}$, is equal to the travel time between these two states. If the initial latitude/longitude position is denoted by $\left(\lambda_{i}, \tau_{i}\right)$ and the final position is denoted by $\left(\lambda_{f}, \tau_{f}\right)$ then the cost/travel time is given by [18]

$$
C\left(x_{k}, u_{k}, k\right)=t=d / V_{k}
$$

where

$$
d=R_{\text {zartat }} \cdot \cos ^{-1}\left[\sin \lambda_{j} \cdot \sin \lambda_{f}+\cos \left(\tau_{f}-\tau_{i}\right) \cdot \cos \lambda_{i} \cdot \cos \lambda_{f}\right]
$$

and

$$
V_{g}=\sqrt{\dot{x}^{2}+\dot{y}^{2}}
$$

Here $\bar{K}_{\text {earth }}$ is the radius of the Earth, which is taken to be $3,444.046647$ tum, and the horizontal components of the velocity are demoted by $\dot{x}$ and $\dot{y}$. These velocity components are calculated from the horizontal velocity of the aircraft, $v_{h}$, the horizontal component of the wind velocity, $w_{h}$, the aitcraft's commanded heading, $\chi_{\text {com }}$, and the horizontal wind direction, $\chi_{k}$, using the following expressions:

$$
\dot{x}=v_{h} \cdot \cos \chi_{c o m}+w_{h} \cdot \cos \chi_{h}
$$

and

$$
\dot{y}=v_{h} \cdot \sin \chi_{\text {com }}-w_{h} \cdot \sin \chi_{h}
$$

The aircraft's command heading, $\chi_{\text {com }}$, is related the course angle for great circle navigation via the following expression:

$$
\chi_{c u m}=\chi_{G C}-\sin ^{-1}\left(\left(w_{h} / v_{h}\right) \cdot \sin \left(\chi_{h}-\chi_{G C}\right)\right)
$$

where

$$
\chi_{G C}=\tan ^{-1}\left[\frac{\sin \left(\tau_{f}-\tau_{i}\right) \cdot \cos \lambda_{f}}{\sin \lambda_{f} \cdot \cos \lambda_{i}-\sin \lambda_{i} \cdot \cos \lambda_{f} \cdot \cos \left(\lambda_{f}-\lambda_{i}\right)}\right]
$$




\section{Acknowledgments}

The authors would like to acknowledge the help of Mr. Kevin Channess and Mr. David M. Maynard from the Federal Aviation Administration for providing the oceanic domain knowledge expertise required to complete this study. The assistance of Mrs. Almira Williams from CSSC, Inc is also acknowledged for contributing to our understanding of flight routing and air traffio procedures in the Pacific Ocean.

\section{References}

"Wu, Y. S., Karakis, T., and Merkle, M., "Perfomance Metrics for Oesanic Air Traftic Management" Air Troffic Control Quavterfy, Vol. 12, No. 4, 2004, pp. 315-338.

2"Air Traffic Control," Otder 7110.65P, Federal Aviation Adthitistration, Feb. 19, 2004.

3. Advanced Techrologies \& Oceanic Procedures (AIUP)", U.S. Dept. of Transportation, Federal Aviation Administration, URL: htto//www faa gov/aituorts airtraffic/tedmolosy/aton

Trotter-Cox, A., "Requited Navigation Performance (RNP)," Professional Filot Magazine, 1999: URL: http:/ www aviationmanuals,com/articles/article3, html.

"Notice of Required Navigation Pexformance 10 (RNP-10) Inplengentation in the Oaklatid Center FIR, Oakland NOTAM A4335/98, Federal Aviation Aduninistration, 1998.

"Ercberger, $\mathrm{H}$. and Lee, H., "Constrained Optimum T"ajectories with Specified hange," AlAA Joumal of Gruidanee, Navigation and Control, Yol. 3, Jan-Feb, 1980, pp. 78-85.

Tardin, M., "Real-Time Conflict Free Trajectory Optimization," $5^{\text {th }}$ USA/Europe ATM 2003 RAD Seminar, Budapest, Huxgary, Juite 23-27,2005.

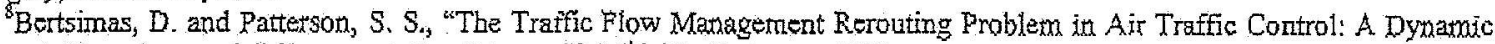
Network Flow Approach," Transportation Science, Vol. 34, No. 3, August 2000.

"Bamhart, C., Bolsnd, N. L, Clarke, L. W., Johneon, G. L., Nomhauser, and G. L., Shonoi, R. G., "Flight String Models fox Aircraft fleeting and Routing," Transportation Sciences, Vol. 32, Issue 3, March 1998.

${ }^{10}$ Jardin, M. "Towgrd Real-Time En Route Air lrafic Control Optimization," Ph.D. Dissertation, Stanford University, Dept. of Acronautics \& Astronautics, April 2003.

"Larson, R. E. and Casti, J. L., Principles of Dynamic Programming: Part I Basic Analytic and Computational Methods, Marcel Dekker; Inc., 1978.

12 Enhanced Traffic Management System (ETMS),"Report No. VNTSC-DTS56-TMS-002, Volpe National Transportation Cenier, U.S. Dept of Transportation, Cambridge, MA, Oct 2005.

13s "Aiteteft Situation Display To Industry: Functional Description and interface Control Document" Report No. ASDI-FD001, Volpe National Transportation Center, U.S. Dept, of Transportation, Cambridge, MA, June 29, 2005.

${ }^{14}$ Bilimoria, K., Sridhar, B., Chatterji, G. B., Sherh, K., and Grabbe, S.; "FACET: Future ATM Concepts Evalution Tool," Air Traffir Control Quarterly, Vol. 9, No. 1, 2001, pp. 1-20.

"EMC Model Documentation." "National Centers for Environmental Predictions, National Oceanic and Atmospheric Administration, URL: http:/fwww.emc.ncep, noaa,gov/modelinfol.

${ }^{16}$ Bertsicaas, D., and Patterson S. S., "The Air Traffic Flow Mangagenent Problem with Enroute Capacitics," Operafions Research, Vol. 46, No. 3, May-June 1998, pp. 406-422.

"Stidhar, B., Sheth, K. S., Grabbe, S., "Airspace Complex and its Application in Air Traffic Management," $2^{\text {nd }}$ USA/Europe Air Traffic Management R\&D Seminar, Orlando, FL, Dec. 7*4, 1998.

${ }^{18}$ Chatterji, G. B., Sridhar, B., and Bilimoria, K. D., "En-toute Trajectory Prediction for Conflict Avoidance and Traffic Manageracnt," AIAA Guidance Navigation apd Conirol Conjerence, San Dígo, CA, July 29-31, 1996. 